Original Article

\title{
Importance of satisfaction level with initiatives toward the national examination: a 4-year cross-sectional study
}

\author{
AkIRA Kubo, RPT, PhD ${ }^{1)}$ \\ 1) Department of Physical Therapy, School of Health Science, International University of Health and \\ Welfare: 2600-1 Kitakanemaru, Otawara-shi, Tochigi 324-8501, Japan.
}

\begin{abstract}
Purpose] This study aimed to examine the importance of the level of satisfaction with initiatives toward the national examination of the physical therapy department based on the relationship between the levels of satisfaction with initiatives toward the national examination of the physical therapy and satisfaction with experiences such as activities for job hunting, graduation research, mock test scores of the national examination, and own effort for computer-based testing according to gender in a four-year cross-sectional study. [Participants and Methods] The participants were 202 males and 158 females who graduated from the International University of Health and Welfare, in March from 2017 to 2020. The levels of satisfaction with initiatives toward the national examination of the physical therapy and satisfaction with experiences were assessed using a visual analog scale. The participants were ranked into four 25th percentile groups based on the visual analog scale score of satisfaction with initiatives toward the national examination of the physical therapy. [Results] There was a significant difference in the level of satisfaction with activities for job hunting and mock test scores of the national examination in both males and females, graduation research in males, and own effort for computer-based testing in females. [Conclusion] It is suggested that the degree of satisfaction with initiatives toward the national examination of the physical therapy is related to the level of satisfaction with student life activities and that there are gender differences in this relationship. Key words: Satisfaction, National examination, Cross-sectional study
\end{abstract}

(This article was submitted Mar. 12, 2021, and was accepted Apr. 19, 2021)

\section{INTRODUCTION}

In a school for physical therapists, the top three reasons for applying were high success rate in the national examination (NE), extensive facilities, including a university hospital, and high employment rate. The ranking of the most important reasons for application was consistent for both exclusive and concurrent entry students ${ }^{1}$. Therefore, many initiatives toward $\mathrm{NE}$ are vital because training schools for physical therapists are required to establish a high NE success rate.

Most training schools for physical therapists have developed their initiatives toward NE. The effects of table devices ${ }^{2}$, e-learning ${ }^{3)}$, and computer-aided instructional system ${ }^{4}$ have been reported. In addition to these initiatives, students generally take mock examinations conducted by publishers.

In our university, examinations and explanations using past questions have been conducted since March, about one year ago, and exam preparation lessons began in September, about six months ago. Furthermore, various flexible responses have been furnished to students with low-ranking results from the mock examinations.

Taking the NE is a significant event that entails a summary of learning from a four-year university course. University teachers should be aware of the level of satisfaction with the initiatives toward the national examination of the physical

Corresponding author. Akira Kubo (E-mail: akubo@iuhw.ac.jp)

(C2021 The Society of Physical Therapy Science. Published by IPEC Inc.

(c) (1) $\odot$ This is an open-access article distributed under the terms of the Creative Commons Attribution Non-Commercial No Deriva-

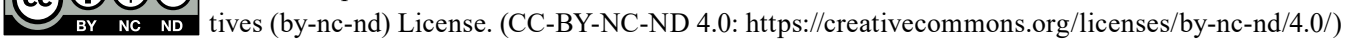


therapy department (SINEPT). We need to verify the satisfaction with one of our educational services for NE.

Therefore, the purpose of this four-year cross-sectional observation study was to examine the importance of the level of the SINEPT from the relationship between the level of the SINEPT and the level of satisfaction with certain experiences such as activities for job hunting (AJH), graduation research (GR), mock test score of national examination (MTS), and own effort for computer-based testing in the third year (CBT) by gender.

\section{PARTICIPANTS AND METHODS}

The participants of this four-year cross-sectional study were 202 male and 158 female physical therapy students who graduated from International University of Health and Welfare, Otawara campus in Tochigi prefecture, in March from 2017 to 2020, and who agreed to participate in this study. Their average age was $22.3 \pm 2.5$ years old (mean \pm SD). Eight participants were excluded from this study because their consent was not obtained. The study was approved by the Ethics Committee of the International University of Health and Welfare (Approval No. 17-Io-122). To protect participant's privacy, we treated the data with care.

The level of the SINEPT, AJH, GR, MTS, and CBT were assessed using a visual analog scale (VAS). This four-year study from 2017 to 2020 was conducted in mid-February, about one week before the NE in the fourth grade, using a standard form based on previous studies ${ }^{5-8)}$. The participants indicated "not at all satisfied" on the left end or "extremely satisfied" on the right end of 100-mm straight line. These all four sessions were conducted by the corresponding author. Specific explanations were not provided to participants regarding the level of satisfaction, because the degree of satisfaction was subjective.

Table 1 indicates the median, minimum, and maximum values for the five items by gender. No significant gender difference was observed using the Mann-Whitney test. The participants were ranked into four 25th percentile groups based on the VAS score of the SINEPT.

In the statistical analysis, the VAS scores of satisfaction with AJH, GR, MTS, and CBT by gender were determined using the Kruskal-Wallis test, and post hoc analysis was conducted using the Bonferroni method to determine the respective differences in each group compared with the others in the four percentile groups. $\mathrm{P}<0.05$ was considered statistically significant. All analyses were performed with IBM SPSS26.0 (IBM Corp., Armonk, NY, USA).

\section{RESULTS}

In the four 25th percentile groups based on the VAS score of SINEPT, the VAS scores of the four items are presented in Table 2 .

In males, there was a significant difference in the level of satisfaction with AJH, GR, and MTS among the four groups by SINEPT. In the post hoc analysis, the first 25 th percentile group was significantly more satisfied with AJH and GR compared to the below 76th group.

In females, there was a significant difference in the level of satisfaction with AJH, MTS, and CBT among the four groups by SINEPT. The post hoc analysis results are as follows: The 1st-25th group was significantly more satisfied with AJH compared with the 51th-75th and below 76th groups. The level of satisfaction with MTS of the top three groups was significantly

Table 1. Median, minimum and maximum values for the five items by gender

\begin{tabular}{lc}
\hline & Median (minimum-maximum) \\
\hline Male (n=202) & \\
VAS level of satisfaction with & $66(2-100)$ \\
$\quad$ initiatives toward national examination & $72(0-100)$ \\
activities for job hunting & $71(3-100)$ \\
graduation research & $56(0-100)$ \\
mock test score of the national examination & $62.5(2-100)$ \\
$\quad$ own effort for CBT in the third year & \\
Female (n=158) & $63(2-95)$ \\
VAS level of satisfaction with & $72(3-100)$ \\
initiatives toward national examination & $70(11-100)$ \\
activities for job hunting & $55.5(0-95)$ \\
graduation research & $60.5(0-100)$ \\
mock test score of the national examination & \\
own effort for CBT in the third year &
\end{tabular}

Median (minimum-maximum), CBT: computer-based testing. 
Table 2. Each satisfaction score in four national examination satisfaction percentile groups by gender

\begin{tabular}{lccccc}
\hline Group & 1st-25th & 26th-50th & 51 th-75th & below 76th & Total \\
\hline Male & $\mathrm{n}=54$ & $\mathrm{n}=48$ & $\mathrm{n}=53$ & $\mathrm{n}=47$ & $\mathrm{n}=202$ \\
VAS level of satisfaction with & & & & & \\
activities for job hunting* & $80(12-100)$ & $71(10-100)$ & $72(5-100)$ & $65(0-100)^{\#}$ & $72(0-100)$ \\
graduation research* & $77(34-100)$ & $72.5(13-97)$ & $72(20-98)$ & $60(3-100)^{\#}$ & $71(3-100)$ \\
mock test score of the national examination* & $60.5(23-100)$ & $61(15-98)$ & $54.5(0-91)$ & $49(4-100)$ & $56(0-100)$ \\
own effort for CBT in the third year & $68(10-100)$ & $67(11-100)$ & $59.5(2-100)$ & $52(8-100)$ & $62.5(2-100)$ \\
& & & & & \\
Female & $\mathrm{n}=41$ & $\mathrm{n}=39$ & $\mathrm{n}=38$ & $\mathrm{n}=40$ & $\mathrm{n}=158$ \\
VAS level of satisfaction with & & & & & \\
activities for job hunting* & $82.5(18-100)$ & $72.5(3-100)$ & $70.5(25-100)^{\S}$ & $68(21-100)^{\#}$ & $72(3-100)$ \\
graduation research & $73(33-100)$ & $69(36-93)$ & $68(11-100)$ & $70(27-100)$ & $70(11-100)$ \\
mock test score of the national examination* & $64.5(3-83)$ & $60(12-94)$ & $54(2-81)^{\S}$ & $38(0-95)^{\sharp \$+}$ & $55.5(0-95)$ \\
own effort for CBT in the third year* & $71.5(14-100)$ & $61(0-88)$ & $58(4-86)$ & $50(15-95)^{\#}$ & $60.5(0-100)$ \\
\hline
\end{tabular}

Kruskal-Wallis test, ${ }^{*} \mathrm{p}<0.05$.

Post hoc analysis by the Bonferroni method.

${ }^{\#} \mathrm{p}<0.05,1$ st-25th vs. below 76 th, ${ }^{{ }} \mathrm{p}<0.05,1$ st-25th vs. 51 th- 75 th.

${ }_{\mathrm{p}}<0.05,26$ th-50th vs. below 76 th, ${ }^{+} \mathrm{p}<0.05,51$ th-75th vs. below 76 th.

Median (minimum-maximum).

CBT: computer-based testing.

higher than that of the below 76th group, and that of the 1st-25th group was significantly higher than that of the 26th-50th and 51th-75th groups. The 1st-25th group was significantly more satisfied with CBT compared with the below 76th group.

\section{DISCUSSION}

The objective of the current study was to examine the importance of the level of SINEPT from the association between SINEPT and satisfaction with the student life activities by gender. The studies regarding students' satisfaction with learning and life have been reported ${ }^{5-8)}$. However, this is the first study focusing on SINEPT conducting an observation study for four years. There was a significant difference in the level of satisfaction with AJH and MTS for both males and females, with GR only in males and with CBT only in female. Therefore, gender differences were observed with regard to the association between SINEPT and satisfaction with the student life activities.

In the post hoc analysis, for both males and females, the level of satisfaction with AJH was significantly higher for the 1 st-25th group compared with that of the below 76 th group. It is presumed that the 1 st- 25 th group is job hunting with a mental leeway because the initiatives toward the NE and activities for job hunting were conducted in overlap periods.

What is characteristic of females is that there is a substantial difference of 25 points or more in the level of satisfaction with MTS between the 1st-25th and the below 76th groups, and significant differences were found between many groups. The 1st-25th group further had a significantly higher score in CBT compared to the below 76th group; therefore, the below 76th group required learning support even before they advance to the final grade.

The limitation of the present study is that the participants were from only one campus, although the number of participants was large. Future studies should include a wider range of participants, as well as other schools.

In conclusion, it is suggested that the degree of SINEPT is related to the level of satisfaction with student life activities and this relationship varies by gender.

\section{Conflict of interest}

The author declares no conflicts of interest in this work.

\section{REFERENCES}

1) Kubo A, Ishizaka M, Sadakiyo K, et al.: Differences in application reasons according to route of college entry of physical therapy department freshmen. Rigakuryoho Kagaku, 2019, 34: 719-722 (in Japanese). [CrossRef]

2) Toriyama M, Ohinata H, Toyoda A, et al.: Effects of tablet devices to learning for passing national examination of physical therapist and the obtaining physical therapy skill. Bull Teikyo Univ Sci, 2017, 13: 271-280 (in Japanese).

3) Takemasa N, Morizane S, Shida K, et al.: Interim report on the effect of the e-learning for national examination result in nurse basic education: Comparison 
with the stage of instructive construction and intensive of e-Learning by learning theory. Bull Teikyo Univ Sci, 2015, 11: 83-93 (in Japanese).

4) Matsumura S, Hashimoto H, Hata A, et al.: Developing computer-aided instructional system for national examinations for medical technologist, clinical engineering technologist and emergency medical technician. Univ Bull Chiba Inst Sci, 2009, 2: 33-36 (in Japanese).

5) Kubo A, Tani H, Kobayashi K, et al.: Level of satisfaction with study and life in the first four months after entering a university physical therapy department Rigakuryoho kagaku, 2016, 31: 625-628 (in Japanese). [CrossRef]

6) Kubo A, Kurosawa K, Maruyama H: Changes in QOL of undergraduate physical therapy students after the Great East Japan Earthquake: satisfaction with life and learning at the end of the junior year of college. Rigakuryoho kagaku, 2014, 29: 1007-1009 (in Japanese). [CrossRef]

7) Kubo A, Kuramoto AT, Kobayashi K, et al: Influence of satisfaction with learning and living at the end of the junior and senior college years of PT students on the results of the national examination for physical therapists. Rigakuryoho kagaku, 2015, 30: 115-117 (in Japanese). [CrossRef]

8) Kubo A, Yoshikawa K, Onoda K: Satisfaction with learning and life in physical therapy student: a 4 year longitudinal study. J Phys Ther Sci, 2021 , 33: $209-212$. [Medline] [CrossRef] 